\title{
Vitamin D status and pain: analysis from the Health Survey for England among English adults aged 65 years and over
}

\author{
Vasant Hirani* \\ Department of Epidemiology and Public Health, University College London Medical School, 1-19 Torrington Place, London \\ WC1E 6BT, UK \\ (Submitted 2 February 2011 - Final revision received 17 May 2011 - Accepted 22 June 2011 - First published online 28 September 2011)
}

\begin{abstract}
Poor vitamin D status is common in older people and results in osteoporosis; osteomalacia is associated with a wide range of non-communicable diseases and has potential effects on poor health outcomes. Pain is also common in older people and can be substantially disabling. The aim of the present analysis is to investigate associations between serum 25-hydroxy vitamin D (25(OH)D) and self-reported current symptoms of pain in a cross-sectional, nationally representative sample of 2070 adults aged $\geq 65$ years living in the community in England in 2005. Measurements included serum 25(OH)D, pain status and covariates, namely, age, sex, social class, season of examination, use of vitamin supplements and physical health status. Results show that the symptoms of moderate/extreme pain (present in $53 \%$ of the sample) were associated with poor vitamin D status, independent of other covariates. Particular advantages of the present study were the presence of directly measured vitamin D levels and a large and nationally representative sample. Poor vitamin D status is common and an associated risk factor for pain in older people living in northern latitudes. The direction of causation cannot be inferred from a crosssectional study and further prospective research is required to clarify this. Regardless of the direction of causation, the relationship is potentially of high public health importance because of the adverse impact of both states on well-being. It is important that older people in pain are screened for vitamin D status and provided with appropriate interventions.
\end{abstract}

Key words: Vitamin D status: Pain: Older people: England: Nationally representative population surveys

Pain is common in older people and can be substantially disabling. It is most commonly associated with poor general health. Poor vitamin D status has been shown in older people living in institutions and in the community ${ }^{(1,2)}$ and can result in higher levels of morbidity and frailty. Older people are at higher risk of poor vitamin D status because of a decline in efficiency of vitamin D synthesis and a lowered renal conversion of vitamin $D$ to its active form ${ }^{(3)}$. Low endogenous production can be compensated for by dietary intake and dietary supplement use; however, in the United Kingdom, dietary intake of vitamin D-containing foods (oily fish, e.g. herring and mackerel, fortified margarines, meat and meat products and eggs) among older people is also poor $^{(4)}$. Winter vitamin $\mathrm{D}$ levels in older people of the United Kingdom have been found to be associated with diet and overseas holidays within the last 6 months, but not with winter sun exposure ${ }^{(5)}$. In the absence of sunlight, $25 \mu \mathrm{g}$ of vitamin $D$ are necessary to maintain a healthy level of 25-hydroxy vitamin D (25(OH)D) above $75 \mathrm{nmol} / \mathrm{l}^{(6)}$. Recent studies have shown associations of poor vitamin D status with chronic pain ${ }^{(7,8)}$, specific musculoskeletal pain ${ }^{(9)}$ and generalised bone and/or muscle pain ${ }^{(10)}$. Observational evidence suggests that there may be a role for vitamin D in the aetiology of chronic pain conditions ${ }^{(11)}$. The importance of vitamin $\mathrm{D}$ in calcium absorption and metabolism for bone health is well known. Poor vitamin D status manifests in osteomalacia, a disorder of bone mineralisation that can cause generalised bone pain. Chronic pain or discomfort may affect the ability to go outdoors and obtain adequate sunlight exposure $^{(12)}$ and may also have an influence on and result in limitations of eating a nutritionally adequate diet rich in vitamin $\mathrm{D}^{(13)}$. The aetiology of pain may also be explained by the influence of the active $1,25(\mathrm{OH}) 2 \mathrm{D}$ form of vitamin $\mathrm{D}$, a potent modulator of inflammation, that may play a role in shutting off chronic inflammatory responses ${ }^{(14)}$; however, it still remains to be an area that is not well established.

The relationship between vitamin $\mathrm{D}$ status and pain is potentially of high public health importance because of the adverse impact of both states on general well-being. In a nationally representative survey of health in older people, the Health Survey for England (HSE), we investigated the association between (25(OH)D) levels and symptoms of pain.

Abbreviations: 25(OH)D, 25-hydroxy vitamin D; HSE, Health Survey for England.

*Corresponding author: V. Hirani, fax +44 207813 0242, email v.hirani@ucl.ac.uk 


\section{Methods}

\section{The sample}

Data were analysed from the 2005 HSE, an annual survey designed to measure health and health-related behaviours in a nationally representative sample of adults and children living in private households in England. The survey has a series of core elements that are included every year and special topics that are included in selected years. In 2005, the HSE included an additional, nationally representative general population sample of English people aged 65 years and over, living in private households ${ }^{(15)}$. Similar to previous surveys in the HSE series, the 2005 survey adopted a multistage stratified probability sampling design using the English Postcode Address File as the primary sampling frame. It comprised a core (general population) sample randomly selected using 7200 addresses in 720 postcode sectors and a boost sample of people aged 65 years and over, selected using 11520 additional addresses at the same 720 postcode sectors as the core sample. Households were screened to identify whether older people were resident and, in these cases, interviews and nurse visits were conducted. The total sample of people aged 65 years and over who were interviewed included 4269 residents ( 723 men and 873 women in the general population sample and 1174 men and 1499 women in the boost sample). The overall response rate among men and women aged 65 years and over was $71 \%$ in the general population sample and $74 \%$ in the boost sample. The sampling design and methodology have been described in more detail elsewhere $^{(16)}$. Ethical approval for the survey was obtained from the North Thames Multi-centre Research Ethics Committee and from relevant Local Research Ethics Committees in England.

Among those aged 65 years and over, who participated in a nurse visit ( $n$ 3145), a blood sample was obtained from $70 \%$ of men and $71 \%$ of women along with written consent. A valid serum 25(OH)D sample was obtained from 2070 participants: 950 men and 1120 women. The mean age of participants who provided a blood sample was 73.7 years compared to 74.5 years for all those interviewed. Blood samples were collected throughout the year from January to December 2005.

\section{Measurements}

The interviewers carried out a computer-aided personal interview with the sample participants. Interviewers collected data on socio-demographic aspects (including age, sex and social class), health behaviours (e.g. smoking) and self-reported general health (subjective general health and extent of limiting health conditions - for the latter, participants were asked whether they had any long-standing illness; those providing an affirmative response were asked whether this limited their daily activities in any way). Questions were asked from the EQ-5D (EuroQol Group Executive Office, The Netherlands) ${ }^{(17,18)}$, an internationally acceptable standardised instrument for health state classification. The EQ-5D is a widely used generic instrument that contains five attributes of health status including mobility, self-care, usual activities, pain/discomfort and anxiety/depression. Each of the attributes is measured by a question with three possible responses, namely, no symptoms, moderate symptoms or extreme symptoms ${ }^{(16)}$. The interest in the present study was to identify current symptoms of pain or discomfort. Degree of pain/ discomfort was assessed at levels: (1) no symptoms; (2) combined level including moderate and extreme symptoms.

After the interviewer visit, those who agreed had a nurse visit within $2-3 \mathrm{~d}$. Nurses collected additional information including information on current medication and vitamin supplement usage; and took measurements including BMI (weight in $\mathrm{kg}$ divided by height in $\mathrm{m}^{2}$ ) and blood pressure and obtained non-fasting blood samples, with assays on these including 25(OH)D analysis. Vitamin D analyses were carried out at the Royal Victoria Infirmary in Newcastle upon Tyne, UK, using the DiaSorin radioimmunoassay kit (DiaSorin, Inc., Stillwater, MN, USA). Full details on blood sample collection and analysis are described elsewhere ${ }^{(16)}$. The timing (month) of the interview was also treated as a covariate. The laboratories performing the $25(\mathrm{OH}) \mathrm{D}$ analyses took part in the Internal and External Quality Assessment Schemes. There were no significant variations in the intra and inter assays for both blood analytes ${ }^{(16)}$.

Vitamin D deficiency has been conventionally defined as serum concentrations of $25(\mathrm{OH}) \mathrm{D}$ below $25 \mathrm{nmol} / \mathrm{l}^{(19)}$. Two other relative deficiency states were also defined for the following reasons: (1) a level below $50 \mathrm{nmol} / 1$ (hypovitaminosis) has been associated with slightly elevated serum parathyroid hormone concentration and mild increase of bone turnover ${ }^{(20)}$; (2) optimal levels are currently considered to be $75 \mathrm{nmol} / 1$ or greater ${ }^{(21)}$. In the present analysis, it was decided to consider the definitions of low vitamin D status as independent variables separately.

\section{Statistical analysis}

Specific statistical weighting was used to correct for nonresponse at each stage, in addition to unequal sample selection, using information available about responders and non-responders. Following a description of the sample, associations between symptoms of pain and the three $25(\mathrm{OH}) \mathrm{D}$ deficiency categories were analysed in logistic regression models ${ }^{(22)}$, with sequential adjustments for demographic factors, supplement intake, followed by adjustments for BMI, reported long-term illness and subjective general health status. Stata 10 software (StataCorp LP, College Station, TX, USA) was used.

\section{Results}

Following sampling, further confirmatory analyses showed that participants for whom vitamin D data had been obtained were representative of those interviewed. For example, mean age was 74.5 years in those interviewed and was 73.7 years in those who gave a blood sample. Furthermore, $44 \%$ of those interviewed and $46 \%$ of those providing a blood sample were male. Income, region and social class were also similar between groups. 
Characteristics of the analysed sample are summarised in Table 1 . The majority of the sample (97\%) was classified as 'white British'. In total, $60 \%$ were aged between 65 and 74 years and $<10 \%$ described poor physical health; however, a substantial proportion had one or more limiting long-standing illness. Examinations were evenly distributed across seasons and 25(OH)D levels showed little variation by season in the sample analysed. The prevalence of symptoms of pain or discomfort was $53.0 \%$ in the total analysed sample. Of those reporting to have moderate or extreme pain, the majority (approximately 60\%) had a doctor-diagnosed musculoskeletal condition and about $40 \%$ had a heart or circulatory system condition. A total of $80 \%$ of those in pain had a limiting or non-limiting long-standing illness.

Logistic regression analyses of the associations between the deficiency states and symptoms of pain are summarised in Table 2. Associations were significant for $25(\mathrm{OH}) \mathrm{D}$ levels $<25 \mathrm{nmol} / 1$ and between 25 and $49.9 \mathrm{nmol} / \mathrm{l}$, even after adjustment; however, for 25(OH)D levels between 50 and
$74.9 \mathrm{nmol} / 1$, associations were not significant before or after adjustment by covariates, except when adjusting by long-standing illness (Table 2, model 6). The most marked reductions in the strength of association for 25(OH)D levels $<25 \mathrm{nmol} / 1$ and between 25 and $49.9 \mathrm{nmol} / 1$ occurred following adjustment for general health status (Table 2)

\section{Discussion}

In an analysis of data from the 2005 HSE, the association between vitamin $\mathrm{D}$ status and symptoms of pain was investigated. Associations were shown for vitamin D status at levels below $25 \mathrm{nmol} / 1$, between 25 and $49.9 \mathrm{nmol} / 1$ and not for milder levels of deficiency $(50-74.9 \mathrm{nmol} / \mathrm{l})$. Marked reductions in the strength of association for 25(OH)D levels $<25 \mathrm{nmol} / 1$ and between 25 and $49 \cdot 9 \mathrm{nmol} / 1$ occurred following adjustment for general health status. The advantages of the present study are the presence of directly measured vitamin D levels, representing the status at the same time period as

Table 1. Descriptive characteristics of informants with a valid serum 25-hydroxy vitamin $D$ $(25(\mathrm{OH}) \mathrm{D})$ values $(\mathrm{nmol} / \mathrm{l})$ included in the analysis and unadjusted associations with extreme or moderate pain

(Odds ratios and $95 \%$ confidence intervals)

\begin{tabular}{|c|c|c|c|c|c|}
\hline Characteristic & No. & Proportion (\%) & OR & $95 \% \mathrm{Cl}$ & $P$ \\
\hline \multicolumn{6}{|l|}{ Age (years) } \\
\hline $65-74$ & 1196 & $60 \cdot 3$ & Ref & & \\
\hline $75+$ & 787 & 39.7 & 1.31 & $1.09,1.57$ & 0.004 \\
\hline \multicolumn{6}{|l|}{ Sex } \\
\hline Male & 910 & $45 \cdot 9$ & Ref & & \\
\hline Female & 1073 & $54 \cdot 1$ & 1.68 & $1 \cdot 40,2 \cdot 01$ & $<0.0001$ \\
\hline \multicolumn{6}{|l|}{ Social class } \\
\hline Non-manual & 1084 & $56 \cdot 3$ & Ref & & \\
\hline Manual & 841 & $43 \cdot 7$ & $1 \cdot 21$ & $0.91,1.60$ & $0 \cdot 18$ \\
\hline \multicolumn{6}{|l|}{ Season } \\
\hline Spring & 457 & $23 \cdot 0$ & Ref & & \\
\hline Summer & 549 & $27 \cdot 7$ & $1 \cdot 10$ & $0.85,1.41$ & 0.46 \\
\hline Autumn & 559 & 28.2 & 0.96 & $0.74,1.23$ & 0.72 \\
\hline Winter & 418 & $21 \cdot 1$ & 0.95 & $0.73,1.25$ & 0.72 \\
\hline \multicolumn{6}{|c|}{ Taking vitamin supplements } \\
\hline Yes & 1087 & $54 \cdot 8$ & Ref & & \\
\hline No & 896 & $45 \cdot 2$ & 1.33 & $1.11,1.61$ & 0.002 \\
\hline \multicolumn{6}{|l|}{ Smoking status } \\
\hline Never & 932 & $47 \cdot 0$ & Ref & & \\
\hline Previous, occasional & 838 & $42 \cdot 3$ & $1 \cdot 10$ & $0.91,1.32$ & 0.34 \\
\hline Current & 212 & $10 \cdot 7$ & 0.97 & $0.72,1.31$ & 0.85 \\
\hline \multicolumn{6}{|l|}{ BMI $\left(\mathrm{kg} / \mathrm{m}^{2}\right)$} \\
\hline Normal (20-25) & 448 & $26 \cdot 6$ & Ref & & \\
\hline Underweight $(<20)$ & 41 & $2 \cdot 4$ & $1 \cdot 20$ & $0.94,1.51$ & 0.14 \\
\hline Overweight $(25-30)$ & 759 & $45 \cdot 0$ & 1.74 & $1 \cdot 33,2 \cdot 27$ & $<0.0001$ \\
\hline Obese (over 30) & 439 & $26 \cdot 0$ & 0.63 & $0.32,1.23$ & 0.18 \\
\hline \multicolumn{6}{|l|}{ Long-standing illnesses } \\
\hline None & 621 & $31 \cdot 3$ & Ref & & \\
\hline Non-limiting & 579 & 29.2 & 2.05 & $1 \cdot 61,2 \cdot 61$ & $<0.0001$ \\
\hline Limiting & 783 & 39.5 & $10 \cdot 82$ & $8.41,13.92$ & $<0.0001$ \\
\hline \multicolumn{6}{|l|}{ General health } \\
\hline Good/very good & 1268 & 63.9 & Ref & & \\
\hline Fair & 538 & $27 \cdot 1$ & 3.27 & $2 \cdot 64,4.06$ & $<0.0001$ \\
\hline Bad/very bad & 177 & 8.9 & $19 \cdot 50$ & $10 \cdot 71,35 \cdot 5$ & $<0.0001$ \\
\hline \multicolumn{6}{|l|}{ Vitamin D levels $(\mathrm{nmol} / \mathrm{l})$} \\
\hline$>75$ & 195 & $14 \cdot 7$ & Ref & & \\
\hline $50-74.9$ & 820 & 41.4 & 1.25 & $0.95,1.64$ & 0.12 \\
\hline $25-49 \cdot 9$ & 676 & $34 \cdot 1$ & 1.58 & $1 \cdot 20,2 \cdot 06$ & 0.001 \\
\hline$<25$ & 292 & $9 \cdot 8$ & $2 \cdot 18$ & $1.50,3 \cdot 16$ & $<0.0001$ \\
\hline
\end{tabular}

Ref, reference category. 
Table 2. Logistic regression analyses for associations between vitamin D status and moderate or extreme pain before and after adjustment for covariates

(Odds ratios and $95 \%$ confidence intervals)

\begin{tabular}{|c|c|c|c|c|c|c|c|}
\hline \multirow[b]{2}{*}{ Model } & \multicolumn{2}{|c|}{$\begin{array}{l}\text { Serum } 25(\mathrm{OH}) \mathrm{D} \\
(<25 \mathrm{nmol} / \mathrm{l})\end{array}$} & \multicolumn{2}{|c|}{$\begin{array}{l}\text { Serum } 25(\mathrm{OH}) \mathrm{D} \\
(25-49.9 \mathrm{nmol} / \mathrm{l})\end{array}$} & \multicolumn{2}{|c|}{$\begin{array}{l}\text { Serum } 25(\mathrm{OH}) \mathrm{D} \\
(50-74.9 \mathrm{nmol} / \mathrm{l})\end{array}$} & \multirow[b]{2}{*}{$P_{\text {trend }}$} \\
\hline & OR & $95 \% \mathrm{Cl}$ & OR & $95 \% \mathrm{Cl}$ & OR & $95 \% \mathrm{Cl}$ & \\
\hline $\begin{array}{l}\text { 1. Unadjusted } \\
P\end{array}$ & $2 \cdot 18$ & $\begin{array}{c}1.50,3.16 \\
<0.001\end{array}$ & 1.58 & ${ }_{0.001}^{1 \cdot 20,2 \cdot 06}$ & $1 \cdot 25$ & $0.12^{0.95,1.64}$ & 0.0001 \\
\hline $\begin{array}{l}\text { 2. Adjusted for age } \\
P\end{array}$ & 2.06 & $\begin{array}{l}1.42,3.00 \\
<0.001\end{array}$ & 1.53 & $0.002^{1 \cdot 17,2 \cdot 01}$ & $1 \cdot 24$ & $\begin{array}{l}0.94,1.63 \\
0.13\end{array}$ & 0.0004 \\
\hline $\begin{array}{l}\text { 3. Model } 2+\operatorname{sex} \\
P\end{array}$ & 1.92 & $\begin{array}{l}1 \cdot 32,2 \cdot 81 \\
0.001\end{array}$ & 1.48 & $\begin{array}{l}1 \cdot 13,1.95 \\
0.005\end{array}$ & $1 \cdot 23$ & $\begin{array}{l}0.93,1.63 \\
0.14\end{array}$ & 0.002 \\
\hline $\begin{array}{l}\text { 4. Model } 3+\text { vitamin supplement intake } \\
P\end{array}$ & $2 \cdot 18$ & $\begin{array}{l}1.48,3.22 \\
<0.001\end{array}$ & 1.59 & $\begin{array}{l}1 \cdot 20,2 \cdot 10 \\
0 \cdot 001\end{array}$ & $1 \cdot 26$ & $\begin{array}{l}0.95,1.67 \\
0.11\end{array}$ & 0.0002 \\
\hline $\begin{array}{l}\text { 5. Model } 4+\text { BMI } \\
P\end{array}$ & 1.98 & $\begin{array}{l}1.34,2.94 \\
0.001\end{array}$ & 1.47 & $\begin{array}{l}1 \cdot 11,1.94 \\
0.008\end{array}$ & $1 \cdot 23$ & $\begin{array}{l}0.92,1.63 \\
0.16\end{array}$ & 0.003 \\
\hline $\begin{array}{l}\text { 6. Model } 5+\text { long-standing limiting } \\
\text { illness (three groups) } \\
P\end{array}$ & 1.62 & $1 \cdot 04,2.52$ & 1.47 & $1.07,2.02$ & 1.41 & $1.02,1.94$ & 0.08 \\
\hline 7. Model $5+$ subjective general health status & $1 \cdot 32$ & $\begin{array}{l}0.03 \\
0.21\end{array}$ & $1 \cdot 30$ & $\begin{array}{l}0.02 \\
0.96,1.75 \\
0.08\end{array}$ & $1 \cdot 18$ & $\begin{array}{l}0.04 \\
0.88,1.59 \\
0.27\end{array}$ & 0.36 \\
\hline
\end{tabular}

25(OH)D, 25-hydroxy vitamin D.

asking about current self-reported presence of pain and a large and nationally representative sample.

Many tissues express vitamin D receptors and therefore a physiological role for vitamin $\mathrm{D}$ has been proposed in a number of organs and organ systems, not limited to the skeleton $^{(23)}$. Recently, an Institute of Medicine report ${ }^{(24)}$ concluded that evidence of the benefits of vitamin D are only convincing for bone health.

Although the area of vitamin D-related pain is not well understood, small-scale studies have shown associations between vitamin D status and pain ${ }^{(10,25)}$; however, there have also been several studies that have found no relationship between vitamin D status and pain ${ }^{(26,27)}$.

There is relatively little research that has investigated this in older people, despite the higher potential impact. Findings from the present study are consistent with other studies in which increased symptoms of pain were only seen in the most severe deficiency state, with no marked increases in association with more mild relative deficiency ${ }^{(7)}$.

Although the EQ-5D is an internationally acceptable standardised instrument for health state classification, there are limitations in its use. It asks about the current state of health, and it has been shown that participants asked this question often consider their views in terms of long-term health state ${ }^{(28)}$. The tool has its advantages such as providing good response rates, and it has also been shown to be highly correlated with other validated measures ${ }^{(29,30)}$. Pain determined by EQ-5D can include acute as well as chronic pain. Participants may report that they are in pain including, for example, headaches, unlikely to be associated with vitamin D status.

Direction of causation is perhaps the most important consideration, and it is possible that pain was a cause rather than a consequence of poor vitamin D status. Several processes may underlie the association. Although it may be biologically plausible that poor vitamin D status caused pain, it is very likely that individuals reporting pain were less likely to spend time outdoors and may also limit their activities, resulting in less sunlight exposure and thus vitamin D deficiency. The evidence for vitamin $\mathrm{D}$ and chronic pain in adults is poor at present because of low quality and insufficient randomised controlled trials in this area of research ${ }^{(11)}$. Further prospective research is required to clarify this finding, as direction of causation cannot be inferred from a cross-sectional study.

Conventional confounding factors were taken into account in the present analysis. Other unmeasured potential confounding factors might include general lifestyle (e.g. the ability/willingness to travel to overseas destinations with higher sunlight exposure), which was not measured in the present study. Another limitation was that the comorbidity relied on selfreport information, which is subject to measurement inaccuracy.

If poor vitamin D status is demonstrated to be a cause of pain, removing it could be an effective public health measure to reduce prevalence of pain in older people. It is becoming increasingly recognised that poor vitamin D status has wider adverse effects than those on bone structure and skeletal integrity. Previous findings have shown reduction in symptoms of pain with vitamin D supplementation in those who were vitamin $\mathrm{D}$ deficient ${ }^{(10,25)}$. In addition, as stated earlier, there are plausible biological pathways that might account for a causal association, including involvement in the inflammatory response ${ }^{(14)}$

Regardless of the direction of causation, the higher than expected co-occurrence of poor vitamin D status and pain is an important public health issue for older populations living in northern latitudes. The clinical implications of these findings are that health professionals should be alerted to complaints presented to them by older people, such as pain, muscle and bone pain, so that appropriate interventions can be provided, as both conditions are common in older people and both have adverse health consequences. 


\section{Acknowledgements}

The author thanks all the staff of the Joint Health Surveys Unit at the Department of Epidemiology and Public Health and the National Centre for Social Research and the participants in the surveys. V. H. initiated the idea of the paper, designed and carried out the analyses, interpreted the results and wrote the manuscript. The HSE 2005, on which the present paper is based, was funded by the English Department of Health. The author is currently funded by the NHS Information Centre for health and social care to work on subsequent Health Surveys for England. The views expressed are those of the author and not of the funders. Data analysis and interpretation were carried out by the author independently of the funding sources, based on the available data. The author had full access to the survey data and had final responsibility for the decision to submit for publication. The funding body played no role in the formulation of the design, methods, subject recruitment, data collection, analysis or preparation of the present paper. Ethical approval for HSE 2005 was obtained from the London MREC. The author declares no conflict of interest.

\section{References}

1. Hirani V \& Primatesta P (2005) Vitamin D concentrations among people aged 65 years and over living in private households and institutions in England: population survey. Age Ageing 34, 485-491.

2. Hirani V, Tull K, Ali A, et al. (2010) Urgent action needed to improve vitamin D status among older people in England. Age Ageing 39, 62-68.

3. Holick MF (2006) High prevalence of vitamin D inadequacy and implications for health. Mayo Clin Proc 81, 353-373.

4. Finch S, Doyle W, Lowe C, et al. (1988) The National Diet and Nutrition Survey: People Aged 65 years and Over. Vol 1: Report of the Diet and Nutrition Survey. London: The Stationery Office.

5. Scragg R, Khaw KT \& Murphy S (1995) Life-style factors associated with winter serum 25-hydroxyvitamin D levels in elderly adults. Age Ageing 24, 271-275.

6. Holick MF (2004) Sunlight and vitamin D for bone health and prevention of autoimmune diseases, cancers, and cardiovascular disease. Am J Clin Nutr 80, Suppl. 6, S1678-S1688.

7. Hicks GE, Shardell M, Miller RR, et al. (2008) Associations between vitamin $\mathrm{D}$ status and pain in older adults: the Invecchiare in Chianti study. Am Geriatr Soc 56, 785-791.

8. Atherton K, Berry DJ, Parsons T, et al. (2009) Vitamin D and chronic widespread pain in a white middle-aged British population: evidence from a cross-sectional population survey. Ann Rheum Dis 68, 817-822.

9. Plotnikoff GA \& Quigley JM (2003) Prevalence of severe hypovitaminosis D in patients with persistent, nonspecific musculoskeletal pain. Mayo Clin Proc 78, 1463-1470.

10. Gloth FM, Lindsay JM, Zelesnick LB, et al. (1991) Can vitamin $\mathrm{D}$ deficiency produce an unusual pain syndrome? Arch Intern Med 151, 1662-1664.
11. Straube S, Derry S, Moore RA, et al. (2010) Vitamin D for the treatment of chronic painful conditions in adults. The Cochrane Database of Systematic Review 2010 issue 1, CD007771.

12. Mithal A, Wahl DA, Bonjour JP, et al. (2009) Global vitamin D status and determinants of hypovitaminosis D. Osteoporos Int 20, $1807-1820$.

13. Holick MF, Matsuoka LY \& Wortsman J (1989) Age, vitamin $\mathrm{D}$, and solar ultraviolet. Lancet ii, 1104-1105.

14. Pedersen LB, Nashold FE, Spach KM, et al. (2007) 1,25-Dihydroxyvitamin D3 reverses experimental autoimmune encephalomyelitis by inhibiting chemokine synthesis and monocyte trafficking. J Neurosci Res 85, 2480-2490.

15. Craig R \& Mindell J (2007) The Health Survey for England 2005: The Health of Older Adults. The Health Survey for England Series. London: The Information Centre.

16. Craig R \& Mindell J (2007) The Health Survey for England 2005. Volume 3: Methodology and Documentation. London: The Information Centre.

17. Brooks R (1996) EuroQol: the current state of play. Health Policy 37, 53-72.

18. EuroQol (2010) http://www.euroqol.org (accessed 11 October 2010)

19. Department of Health (1998) Nutrition and Bone Health: With Particular Reference to Calcium and Vitamin D. Report on Health and Social Subjects 49. London: The Stationery Office.

20. Zittermann A (2003) Vitamin D in preventative medicine: are we ignoring the evidence? BrJ Nutr 89, 552-572.

21. Vieth R, Bischoff-Ferrari H, Boucher BJ, et al. (2007) The urgent need to recommend an intake of vitamin $D$ that is effective. Am J Clin Nutr 85, 649-650.

22. Agresti A (2002) Categorical Data Analysis. 2. New York, NY: Wiley.

23. Holick MF (2004) Vitamin D: importance in the prevention of cancers, type 1 diabetes, heart disease, and osteoporosis. Am J Clin Nutr 79, 362-371.

24. Food and Nutrition Board, Institute of Medicine (2011) Dietary Reference Intakes for Calcium and Vitamin D. Washington, DC: National Academies Press. http://www.iom.edu/ Reports/2010/Dietary-Reference-Intakes-for-Calcium-andVitamin-D.aspx (accessed 21 December 2010).

25. Al Faraj S \& Al Mutairi K (2003) Vitamin D deficiency and chronic low back pain in Saudi Arabia. Spine 28, 177-179.

26. Basaran S, Guzel R, Coskun-Benlidayi I, et al. (2007) Vitamin D status: effects on quality of life in osteoporosis among Turkish women. Qual Life Res 16, 1491-1499.

27. Helliwell PS, Ibrahim GH, Karim Z, et al. (2006) Unexplained musculoskeletal pain in people of South Asian ethnic group referred to a rheumatology clinic-relationship to biochemical osteomalacia, persistence over time and response to treatment with calcium and vitamin D. Clin Exp Rheumatol 24, 424-427.

28. Hulme C, Long AF, Kneafsey R, et al. (2004) Using the EQ-5D to assess health-related quality of life in older people. Age Ageing 33, 504-507.

29. Brazier JE, Walters SJ, Nicholl JP, et al. (1996) Using the SF-36 and EuroQol on an elderly population. Qual Life Res $\mathbf{5}$, 195-204.

30. Coast J, Peters TJ, Richards SH, et al. (1998) Use of the EuroQol among elderly acute patients. Qual Life Res 7, 1-10. 